
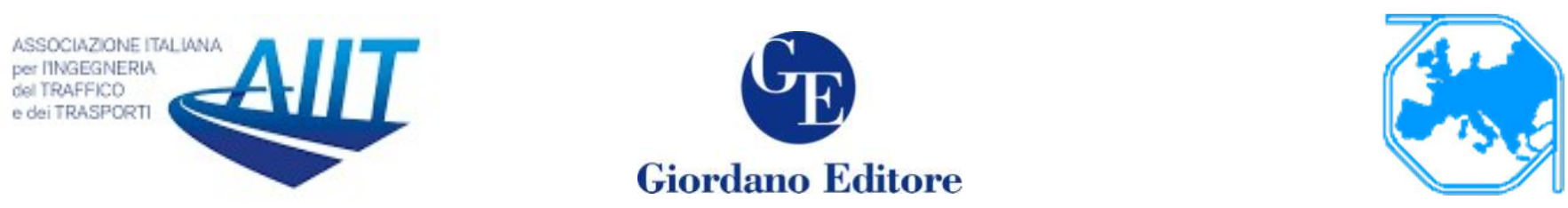

\title{
Testing roundabout capacity models: a practical aid for choosing the right one based on total capacity calculation
}

\author{
Raffaele Mauro ${ }^{1}$, Marco Guerrieri ${ }^{1}$, Andrea Pompigna ${ }^{1 *}$ \\ ${ }^{1}$ DICAM, University of Trento, via Mesiano 77 - 38123 Trento
}

\begin{abstract}
The determination of efficiency measures, under a known traffic demand, is a central aspect of roundabouts analysis. Many capacity formulations have been available for some time in different countries relating to different roundabout layouts. This paper refers to fifteen roundabout entry capacity models used above all in the European countries, highlighting their input requirements and their algorithm complexity. The formulations reviewed are then compared referring to a test roundabout, with a simple and widespread layout. Monte Carlo simulation have been performed considering 5,000 traffic distribution matrices for each capacity model. The results obtained are critically assessed resorting to the calculation of roundabout total capacity. The probability distributions of total capacity allow finding a model that stands out among all as an advisable choice for a suitable capacity formulation, acting as a synthesis of all those examined. This can be of considerable use in view of practical applications, for the design of efficient and safe roundabout intersections in situations in which a country-specific capacity formulation is not available.
\end{abstract}

Keywords: roundabout capacity models; single lane roundabout; entry capacity, total capacity, probability distribution.

\section{Introduction}

As it is well known, the capacity of a highway facility describes the maximum throughput of traffic demand that can be accommodated under current operating conditions. For this reason, capacity plays a fundamental role in highway facilities research, and it is essential for their planning and design.

This situation also fully concerns roundabouts, which have now conquered a space of absolute prominence among at-grade road junctions, and which are the subject of constant research in highway engineering, also with innovative design solutions for greater safety performance (Tollazzi et al., 2016)

Many of these aspects concern the modelling of roundabouts performances towards road users, commonly expressed in terms of the delays to cross the junctions and the consequent queues that can characterize their functioning. Actually, queues and delays assume the role of Measures Of Effectiveness (MOE) of the functioning of the intersection, and they are the basis of the procedures proposed by the main reference for

\footnotetext{
* Corresponding author: Andrea Pompigna (andrea.pompigna3@gmail.com)
} 
the assessment of highway facilities, i.e. the American Highway Capacity Manual - HCM (TRB, 2016). In addition, these aspects of measuring the operational quality of the intersection by modelling the waiting phenomena and the delays that users spend to perform the manoeuvres require more in-depth mathematical tools than the most common queue theory formulas (Mauro and Pompigna, 2020). For these reasons, the HCM provides approximate solutions which, although with some limitations, allow to face the problem in a conventional way. For these models and procedures, both in theoretical implications and in conventional applications, the topics related to "what it is and how much the capacity for a roundabout is worth" are of great interest in highway engineering research and practice.

Here, we can say that the performance analyses of roundabouts are founded on the hypothesis that the circulatory carriageway and the exits are always undersaturated. Consequently, congestion phenomena may occur only at the entries and capacity refers commonly to the capacity of each roundabout entry, the so-called entry capacity (EC) (Mauro, 2010). Thus, if $\mathrm{i}=1,2, \ldots, \mathrm{n}$ is a generic junction arm and $\mathrm{t}$ is a certain time instant, for a roundabout as in Fig. 1a ECs are represented by a vector $\mathbf{C}(t)=\left[\mathrm{C}_{\mathrm{i}}(\mathrm{t})\right]$. The methods by which the components of this vector can be calculated are constantly subject to interest and attention, and this has given rise to various approaches and models that allow to express and to evaluate each component $\mathrm{C}_{\mathrm{i}}$.

Speaking in general, the ECs vector $\mathbf{C}(\mathrm{t})$ or, more simply, every component $\mathrm{C}_{\mathrm{i}}$, can be considered as a function $\mathrm{C}_{\mathrm{i}}=\mathrm{f}(\mathbf{Q}, \mathbf{G}, \boldsymbol{\Theta})$ of some other vectors of variables and parameters, such as: traffic demand variables $\mathbf{Q}$ (e.g., entry flow, traffic distributions for exit, opposing flow); geometric parameters $\mathbf{G}$ (e.g., legs number, diameter length, number and width of entry and ring lanes, entry radius, entry angle, etc.); and other driver/vehicle parameters $\Theta$ (Macioszek, 2020; Pompigna et al., 2020). The ways in which these relationships can be studied and described are manifold, and they characterize the different models that several researches have carried out over the years.

Whatever the model, EC relates to traffic demand and, in particular, with entry and circulating flows, which can be considered as the components of the vector $\mathbf{Q}(\mathrm{t})$. For the generic roundabout of Figure 1a, all the possible components of the vector $\mathbf{Q}(\mathrm{t})$ are determined if we know:

- the entry traffic demand expressed by a vector

$$
\mathbf{Q}_{\mathrm{e}}(\mathrm{t})=\left[\mathrm{Q}_{\mathrm{ei}}(\mathrm{t})\right] \quad \mathrm{i}=1,2, \ldots, \mathrm{n}
$$

- a traffic distribution matrix (origin/destination percentage matrix) (Fig. 1b)

$$
\mathbf{P}_{\mathrm{O} / \mathrm{D}}(\mathrm{t})=\left[\mathrm{P}_{\mathrm{ij}}(\mathrm{t})\right] \mathrm{i}, \mathrm{j}=1,2, \ldots, \mathrm{n}
$$

The origin/destination matrix of traffic demand $\mathbf{M}_{\mathrm{O} / \mathrm{D}}(\mathrm{t})$ from entries "i" to exits " $\mathrm{j}$ " of the roundabout is obtained multiplying each element of the row " $\mathrm{i}$ " of $\mathbf{P}_{\mathrm{O} / \mathrm{D}}(\mathrm{t})$ matrix (2) by the corresponding element $\mathrm{Q}_{\mathrm{ei}}(\mathrm{t})$ of vector (1):

$$
\mathbf{M}_{\mathrm{O} / \mathrm{D}}(\mathrm{t})=\mathbf{P}_{\mathrm{O} / \mathrm{D}}(\mathrm{t}) \cdot \mathbf{Q}_{\mathrm{e}}(\mathrm{t})=\left[\mathrm{Q}_{\mathrm{ij}}(\mathrm{t})\right] \quad \mathrm{i}, \mathrm{j}=1,2, \ldots, \mathrm{n}
$$

In case of steady-state system - in other words, when traffic demand does not vary with time, and, moreover, the traffic flows are served by the roundabout without congestion phenomena - the traffic demand vector and the percentage origin/destination matrix are constant: $\mathbf{Q}_{\mathrm{e}}(\mathrm{t})=\mathbf{Q}_{\mathrm{e}} ; \mathbf{P}_{\mathrm{O} / \mathrm{D}}(\mathrm{t})=\mathbf{P}_{\mathrm{O} / \mathrm{D}}$. In addition, the entry flow $\mathrm{Q}_{\mathrm{e}, \mathrm{i}}$ for each arm is $\mathrm{Q}_{\mathrm{e}, \mathrm{i}}<$ $\mathrm{C}_{\mathrm{i}}$, where $\mathrm{C}_{\mathrm{i}}$ is the EC for arm " $\mathrm{i}$ ", which is also constant (Mauro, 2010). 


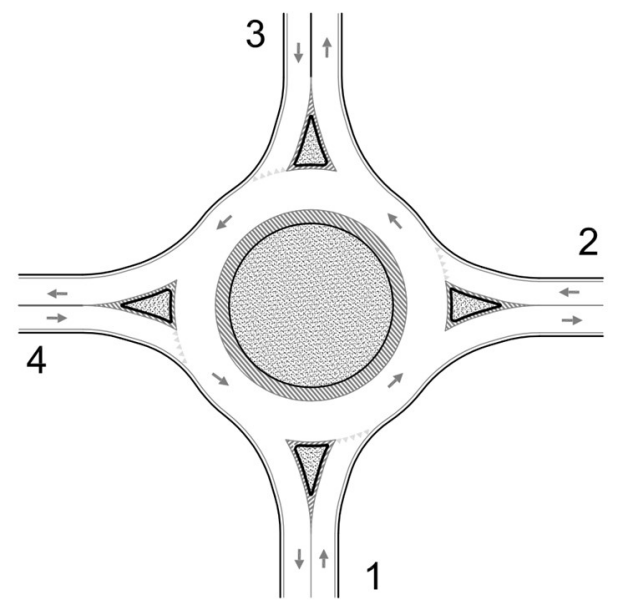

(A)

\begin{tabular}{|c|c|c|c|c|}
\hline $\mathrm{P}_{\mathrm{O} / \mathrm{D}}$ & 1 & 2 & 3 & 4 \\
\hline 1 & $\mathrm{P}_{11}$ & $\mathrm{P}_{12}$ & $\mathrm{P}_{13}$ & $\mathrm{P}_{14}$ \\
\hline 2 & $\mathrm{P}_{21}$ & $\mathrm{P}_{22}$ & $\mathrm{P}_{23}$ & $\mathrm{P}_{24}$ \\
\hline 3 & $\mathrm{P}_{31}$ & $\mathrm{P}_{32}$ & $\mathrm{P}_{33}$ & $\mathrm{P}_{34}$ \\
\hline 4 & $\mathrm{P}_{41}$ & $\mathrm{P}_{42}$ & $\mathrm{P}_{43}$ & $\mathrm{P}_{44}$ \\
\hline
\end{tabular}

(B)

Figure 1: (A) Roundabout with $\mathrm{n}=4$ arms; (B) $\mathrm{P}_{\mathrm{O} / \mathrm{D}}$ matrix.

Following a widespread approach, the EC models for roundabouts can be divided into three main categories: the regression or empirical models, the gap acceptance models, and the microsimulation-based models (Mauro, 2010; Yap et al., 2013; Macioszek, 2020). Empirical models estimate entry capacity through multivariate regression models with the conflict volumes and any other variables affecting capacity, often related with the geometric characteristics of the intersection (Mauro, 2010), relying on field data. Some entry capacity models of widespread use belong to this group, including Kimber (1980), SETRA (1987), CERTU (1998), VSS/Emch (Bovy et al., 1991), Stuwe (1991), Polus and Shmueli (1997), Aakre (1997), and NRW (Brilon et al., 1993). Although these models are heavily influenced by the location and size of the survey samples, as well as by statistical analysis techniques, the parameters that have been calibrated on specific situations are often used as general cases and applied also outside the original contexts. Gap acceptance models relate roundabout capacity to the characterization of driving behaviours through microscopic traffic variables, such as critical gap and follow-up time. Gap acceptance models use different headway distributions, with parameters that can be empirically calibrated on real data. Purely by way of example, but not exhaustively, we can mention here Troutbeck (Akçelik and Troutbeck, 1991), Explorer (Van Arem, 1992), Brilon (Brilon et al., 1993), Brilon-Wu (Mauro, 2010), Vejdirektoratet (1999), HCM 2010 (TRB, 2010), HCM 2016 (TRB, 2016) (for an in-depth analysis, see (Guo et al., 2019)). It is worth noting that, although it is possible to obtain context-specific information thanks to widespread traffic data acquisition technologies, psychotechnical time values from literature are often used, without delving into the specificity of the design site. Micro-simulations models have spread enormously in recent years, with varied solutions based on commercial (e.g., Paramics (SIAS, 2019), Aimsun (TSS, 2019), and Vissim (PTV, 2019)) or open source (e.g., SUMO (Behrisch et al., 2019)) proprietary simulation programs, or using for example discrete event simulations (e.g., (Bakhsh, 2020)), game theory (e.g., (Banjanovic-Mehmedovic et al., 2016; Tian et al., 2018)), multi agent systems (e.g., (Doniec et al., 2008)), cellular automata (e.g., (Wang et al., 2005; Małecki, 2017)), and various artificial intelligence learning approaches (e.g., (Gritschneder et al., 2016; Zhao et al., 2017; Capasso et al., 2020)). Despite having a great flexibility allowing to manage an extremely large number of events, these models require significant efforts to produce case-by-case implementations, with considerable efforts in 
calibration and application to real cases. Once again, however, the transferability of calibrated micro-simulation parameters is worthy of great attention (Gallelli et al., 2017).

As seen from the concise review of the models shown above, many models have been developed and detailed for specific national contexts. Therefore, transferability to different contexts is an effective issue, as in other application fields of highway engineering (Pompigna and Rupi, 2015; Pompigna and Rupi, 2017).

Thus, the aim of this work is to help identifying which model, among the most popular ones, is best suited for the analysis of a roundabout, especially in cases where there are no country-specific references. In this paper we deal with the basic case of a single lane roundabout (i.e., one lane on the ring and one lane at the entrances), focusing on the most common case of a four-arm intersection. A case study with a single-lane roundabout (external diameter $\mathrm{D}=40 \mathrm{~m}$ ) with four arms (Fig. 1a) has been considered, first by comparing EC values according with fifteen different capacity models widespread in practice.

As many researches adopt only the concept of EC for comparison purposes, without considering what can be generated in the roundabout junction as a whole, this study aims at overcoming these limitations and suggests a comparison in terms of total capacity (TC) (Mauro, 2010).

Actually, with respect to a given percentage origin/destination matrix $\mathbf{P}_{\mathrm{O} / \mathrm{D}}, \mathrm{TC}$ is the sum of the flows from each entry $Q_{e, i}$ that are simultaneously equal to $E C\left(Q_{e, i}=C_{i}\right)$, that is:

$$
\mathrm{TC}=\sum_{\mathrm{i}=1}^{\mathrm{n}} \mathrm{Q}_{\mathrm{e}, \mathrm{i}} \quad \text { with } \quad \mathrm{Q}_{\mathrm{e}, \mathrm{i}} / \mathrm{C}_{\mathrm{i}}=1 \quad \text { for } \quad \mathrm{i}=1,2, \ldots, \mathrm{n}
$$

Entry flows to be considered in Eq. (4) are obtained by solving a system of equations in the $n$ unknowns $Q_{e, i}$. Each of these equations is obtained by writing the specific relation for a certain EC model $C_{i}=f(\mathbf{Q}, \mathbf{G}, \boldsymbol{\Theta})$ and replacing $C_{i}$ with the unknown $Q_{e, i}$. As TC clearly depends on the shape of the $\mathbf{P}_{\mathrm{O} / \mathrm{D}}$ matrix, in this research a wide possibility of variation of the $\mathbf{P}_{\mathrm{O} / \mathrm{D}}$ matrix is explored by considering 5,000 different $\mathbf{P}_{\mathrm{O} / \mathrm{D}}$ cases. Through Montecarlo simulations, and then with a large number of TC values for each EC model, the probability distributions of TC can be estimated from simulations.

Then, comparing the simulated probability distributions for $\mathrm{TC}$, similarities and differences emerge among the fifteen models. These results can provide a practical aid for choosing the right EC model allowing to identify a suitable capacity formulation in view of practical applications, especially in absence of country-specific reference formulas.

\section{Material and Methods}

In the present study the following fifteen capacity models have been compared (Tab. 1): Kimber (1980), SETRA (1987), CERTU (1998), VSS/Emch (Bovy et al., 1991), Stuwe (1991), Polus and Shmueli (1997), Aakre (1997), NRW (Brilon et al., 1993), Troutbeck (Akçelik and Troutbeck, 1991), Explorer (Van Arem, 1992), Brilon (Brilon et al., 1993), Brilon-Wu (Mauro, 2010), Vejdirektoratet (1999), HCM 2010 (TRB, 2010), and HCM 2016 (TRB, 2016). Table 2 shows the roundabout geometric parameters, the drivers' psychotechnical parameters, the respective symbols used in the EC models of Tab. 1, and the values adopted for the single-lane roundabout under study. 
Table 1: Entry Capacity (EC) models.

\begin{tabular}{|c|c|}
\hline Model & Entry Capacity \\
\hline Kimber (1980) & $\begin{array}{l}\mathrm{C}=\mathrm{k}\left(\mathrm{F}-\mathrm{f}_{\mathrm{c}} \cdot \mathrm{Q}_{\mathrm{c}}\right) ; \mathrm{f}=303 \cdot \mathrm{x} ; \mathrm{f}_{\mathrm{c}}=0.210 \cdot \mathrm{t}^{*}(1+0.2 \cdot \mathrm{x}) \\
\mathrm{k}=1-0.00347 \cdot(\varphi-30)-0.978 \cdot\left(\frac{1}{\mathrm{r}}-0.05\right) \\
\mathrm{t}^{*}=1+\frac{0.5}{1+\mathrm{e}^{\left(\frac{\mathrm{D}-60}{10}\right)}} ; \mathrm{x}=\mathrm{c}+\frac{\mathrm{e}-\mathrm{c}}{1+2 \mathrm{~S}} ; \mathrm{S}=1.6 \cdot \frac{\mathrm{e}-\mathrm{c}}{\mathrm{L}}\end{array}$ \\
\hline SETRA (1987) & $\begin{array}{l}\mathrm{C}=\left(1330-0.7 \cdot \mathrm{Q}_{\mathrm{d}}\right) \cdot[1+0.1 \cdot(\mathrm{ENT}-3.5)] \\
\mathrm{Q}_{\mathrm{d}}=\left(\mathrm{Q}_{\mathrm{c}}+\frac{2}{3} \cdot \mathrm{Q}_{\mathrm{u}}^{\prime}\right) \cdot[1-0.085 \cdot(\mathrm{ANN}-8)] \\
\mathrm{Q}_{\mathrm{u}}^{\prime}=\mathrm{Q}_{\mathrm{u}} \cdot\left(1-\frac{\mathrm{SEP}}{15}\right) ; \quad \mathrm{Q}_{\mathrm{u}}^{\prime}=0 \text { if } \mathrm{SEP} \geq 15 \mathrm{~m}\end{array}$ \\
\hline CERTU (1988) & $\begin{array}{l}\mathrm{C}=\left(1500-\frac{5}{6} \cdot \mathrm{Q}_{\mathrm{d}}\right) \\
\alpha=0.2(\text { typical value}) ; 0.7 \leq \beta \leq 1 \text { (function of } \mathrm{D} \text { and } \mathrm{ANN}) \\
\mathrm{Q}_{\mathrm{d}}=\beta \cdot \mathrm{Q}_{\mathrm{c}}+\alpha \cdot \mathrm{Q}_{\mathrm{u}}\end{array}$ \\
\hline VSS/Emch (1989) & $\begin{array}{lll}\mathrm{C}=1300-0.75 \mathrm{Q}_{\mathrm{c}} & \text { if } & \mathrm{e} \leq 1.5 \cdot \mathrm{c} \\
\mathrm{C}=1450-0.85 \mathrm{Q}_{\mathrm{c}} & \text { if } & \mathrm{e}>1.5 \cdot \mathrm{c}\end{array}$ \\
\hline Troutbeck (1989) & $\begin{array}{l}\mathrm{C}=3600 \cdot \frac{\alpha \cdot \mathrm{Q}_{\mathrm{c}} \cdot \mathrm{e}^{-\lambda\left(\mathrm{t}_{\mathrm{c}}-\Delta\right)}}{1-\mathrm{e}^{-\lambda \cdot \mathrm{t}_{\mathrm{f}}}} ; \lambda=\frac{\alpha \cdot \mathrm{Q}_{\mathrm{c}}}{1-\Delta \cdot \mathrm{Q}_{\mathrm{c}}} ; \alpha=0.8-0.0005 \cdot \mathrm{Q}_{\mathrm{c}} \\
\mathrm{t}_{\mathrm{c}}=\mathrm{t}_{\mathrm{f}} \cdot\left(3.6135-0.0003137 \cdot \mathrm{Q}_{\mathrm{c}}-0.339 \cdot \mathrm{e}-0.2775\right. \\
\mathrm{t}_{\mathrm{f}}=3.37-0.000394 \cdot \mathrm{Qc}-0.0208 \cdot \mathrm{D}+0.0000889 \cdot \mathrm{D}^{2}-0.395+0.388\end{array}$ \\
\hline Stuwe (1991) & $\mathrm{C}=1089 \cdot \exp \left(-7.42 / 10000 \cdot \mathrm{Q}_{\mathrm{c}}\right)$ \\
\hline Explorer (1992) & $\mathrm{C}=3600 \cdot\left(1-\mathrm{Q}_{\mathrm{d}} \cdot \mathrm{t}_{\min }\right) \cdot \frac{\mathrm{Q}_{\mathrm{d}} \cdot \mathrm{e}^{-\mathrm{Q}_{\mathrm{d}} \cdot\left(\mathrm{t}_{\mathrm{c}}-\mathrm{t}_{\min }\right)}}{1-\mathrm{e}^{-\mathrm{Q}_{\mathrm{d}} \cdot \mathrm{t}_{\mathrm{f}}}} ; \mathrm{Q}_{\mathrm{d}}=\frac{\mathrm{Q}_{\mathrm{c}}+0.5 \cdot \mathrm{Q}_{\mathrm{u}}}{3600}$ \\
\hline $\begin{array}{l}\text { Polus, Shmueli } \\
\text { (1997) }\end{array}$ & $\mathrm{C}=394 \cdot \mathrm{D}^{0.31} \cdot \mathrm{e}^{-0.00095 \cdot \mathrm{Q}_{\mathrm{c}}}$ \\
\hline Brilon (1997) & $\mathrm{C}=1218-0.74 \cdot \mathrm{Q}_{\mathrm{c}}$ \\
\hline Aakre (1998) & $\mathrm{C}=275 \cdot \mathrm{x}-0.282 \cdot \mathrm{Q}_{\mathrm{c}} \cdot(1+0.2 \cdot \mathrm{x}) ; \mathrm{x}=\mathrm{c}+\frac{\mathrm{e}-\mathrm{c}}{1+2 \mathrm{~S}} ; \mathrm{S}=1.6 \cdot \frac{\mathrm{e}-\mathrm{c}}{\mathrm{L}}$ \\
\hline NRW (1999) & $\mathrm{C}=1200-(1.27-0.021 \cdot \mathrm{D}) \cdot \mathrm{Q}_{\mathrm{c}}$ with $13 \mathrm{~m} \leq \mathrm{D} \leq 26 \mathrm{~m}$ \\
\hline Brilon-Wu (2001) & $\mathrm{C}=3600 \cdot\left(1-\mathrm{t}_{\min } \cdot \mathrm{Q}_{\mathrm{c}} / 3600\right) \cdot \frac{1}{\mathrm{t}_{\mathrm{f}}} \cdot \exp \left[-\frac{\mathrm{Q}_{\mathrm{c}}}{3600} \cdot\left(\mathrm{t}_{\mathrm{c}}-\frac{\mathrm{t}_{\mathrm{f}}}{2}-\mathrm{t}_{\min }\right)\right]$ \\
\hline $\begin{array}{l}\text { Vejdirektoratet } \\
(1999)\end{array}$ & $\mathrm{C}=\frac{\mathrm{Q}_{\mathrm{c}} \cdot \mathrm{e}^{\frac{-\mathrm{Q}_{\mathrm{c}} \cdot \mathrm{t}_{\mathrm{c}}}{3600}}}{1-\mathrm{e}^{\frac{-\mathrm{Q}_{\mathrm{c}} \cdot \mathrm{t}_{\mathrm{f}}}{3600}}}$ \\
\hline HCM 2010 & $\mathrm{C}=1130 \cdot \mathrm{e}^{-0.001 \cdot \mathrm{Q}_{\mathrm{c}}}$ \\
\hline HCM 2016 & $\mathrm{C}=1380 \cdot \mathrm{e}^{-0.00102 \cdot \mathrm{Q}_{\mathrm{c}}}$ \\
\hline
\end{tabular}

Figure 2 shows EC values according to the fifteen models in Tab. 1. For each model, as EC for a generic arm i is $C_{i}=f(\mathbf{Q}, \mathbf{G}, \boldsymbol{\Theta})$ and $(\mathbf{G}, \boldsymbol{\Theta})$ assume values in Tab. 2, the entry capacity $\left(\mathrm{pcu} / \mathrm{h}\right.$ ) can be expressed as a function of circulating flow $\mathrm{Q}_{\mathrm{c}}$ (or $\mathrm{Q}_{\mathrm{d}}$ for those 
models that consider other components as well as the circulating one to consider some disturbance). The maximum EC values, obtained for a circulating flow $\mathrm{Q}_{\mathrm{d}}=0 \mathrm{pcu} / \mathrm{h}$, range between a minimum of $1,080 \mathrm{pcu} / \mathrm{h}$ (Aakre model) and a maximum of $1,500 \mathrm{pcu} / \mathrm{h}$ (CERTU model).

Table 2: Parameters used in the EC models of Tab. 1 for the test roundabout.

\begin{tabular}{|c|c|c|}
\hline Parameter & Description & Value adopted \\
\hline $\mathrm{D}$ & Inscribed circle diameter & $40 \mathrm{~m}$ \\
\hline $\mathrm{e}=\mathrm{ENT}$ & Entry width & $4 \mathrm{~m}$ \\
\hline $\mathrm{c}$ & Lane width & $3.5 \mathrm{~m}$ \\
\hline $\mathrm{L}$ & Flare mean length & $10 \mathrm{~m}$ \\
\hline$\phi$ & Entry angle & $35^{\circ}$ \\
\hline $\mathrm{r}$ & Entry bend radius & $15 \mathrm{~m}$ \\
\hline $\mathrm{C}$ & Entry capacity & - \\
\hline $\mathrm{Q}_{\mathrm{c}}$ & circulating flow & - \\
\hline $\mathrm{Q}_{\mathrm{d}}$ & disturbance flow & - \\
\hline $\mathrm{Q}_{\mathrm{u}}$ & exiting flow & - \\
\hline$t_{c}$ & critical gap & $4.1 \mathrm{~s}$ \\
\hline$t_{\min }$ & Min. gap between succeeding vehicles on the circle & $2.1 \mathrm{~s}$ \\
\hline$t_{f}$ & follow-up time & $2.9 \mathrm{~s}$ \\
\hline SEP & splitter island & $7.5 \mathrm{~m}$ \\
\hline ANN & circulatory roadway width & $7 \mathrm{~m}$ \\
\hline
\end{tabular}

It goes without saying that the values of $\mathrm{Q}_{\mathrm{c}}$ (and then $\mathrm{Q}_{\mathrm{d}}$, when it is present in the model), which are taken here incrementally to test the results of each model, can be obtained through linear relationships on the basis of the $\mathbf{M}_{\mathrm{O} / \mathrm{D}}$ matrix in the actual traffic conditions to be analysed (Mauro, 2010).

SETRA

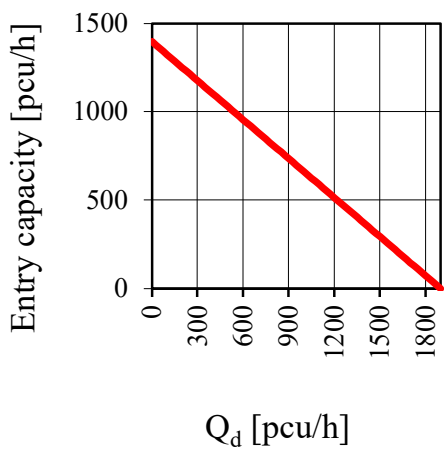

Explorer

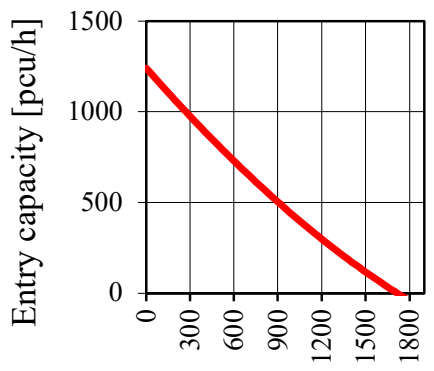

$\mathrm{Q}_{\mathrm{d}}[\mathrm{pcu} / \mathrm{h}]$
Kimber

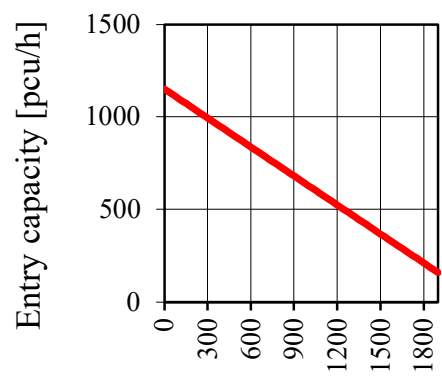

$\mathrm{Q}_{\mathrm{c}}[\mathrm{pcu} / \mathrm{h}]$ 
Aakre

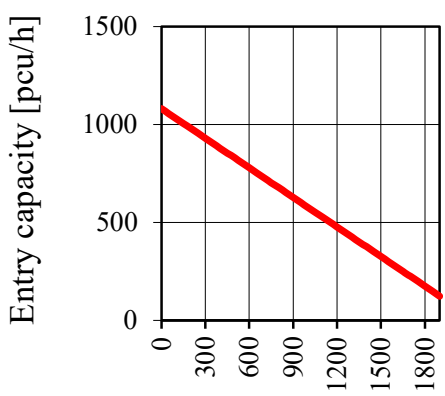

$\mathrm{Q}_{\mathrm{c}}[\mathrm{pcu} / \mathrm{h}]$

NRW

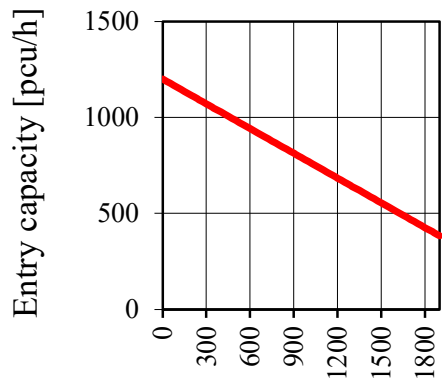

$\mathrm{Q}_{\mathrm{c}}[\mathrm{pcu} / \mathrm{h}]$

CERTU

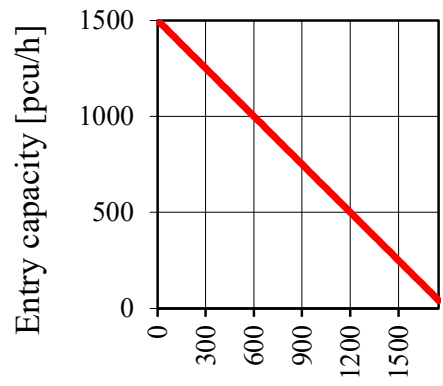

$\mathrm{Q}_{\mathrm{d}}[\mathrm{pcu} / \mathrm{h}]$

HCM 2010

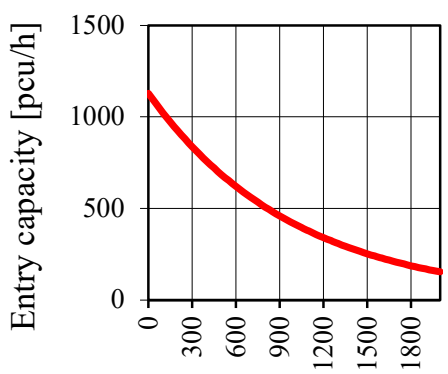

$\mathrm{Q}_{\mathrm{c}}[\mathrm{pcu} / \mathrm{h}]$
Polus, Shmueli

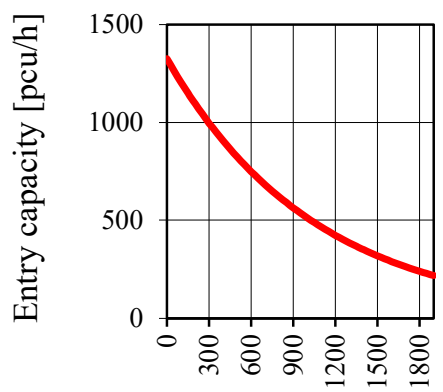

$\mathrm{Q}_{\mathrm{c}}[\mathrm{pcu} / \mathrm{h}]$

Troutbeck

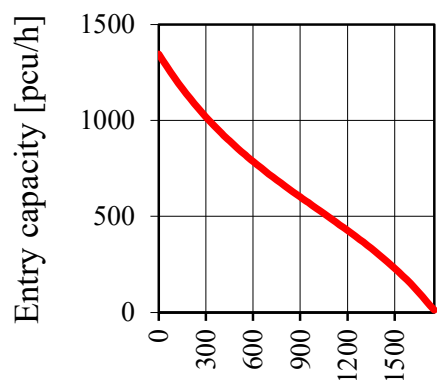

$\mathrm{Q}_{\mathrm{c}}[\mathrm{pcu} / \mathrm{h}]$

Brilon

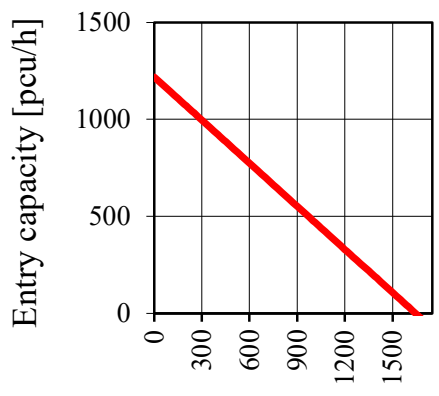

$\mathrm{Q}_{\mathrm{c}}[\mathrm{pcu} / \mathrm{h}]$

HCM 2016

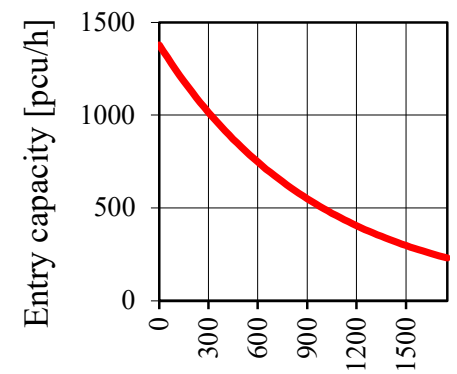

$\mathrm{Q}_{\mathrm{c}}[\mathrm{pcu} / \mathrm{h}]$
VSS/Emch

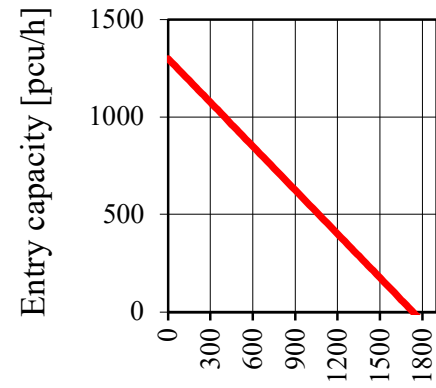

$\mathrm{Q}_{\mathrm{c}}[\mathrm{pcu} / \mathrm{h}]$

Stuwe

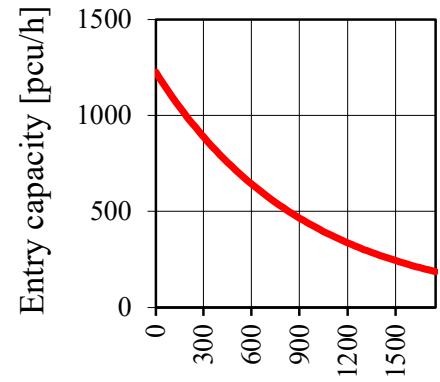

$\mathrm{Q}_{\mathrm{c}}[\mathrm{pcu} / \mathrm{h}]$

Brilon-Wu

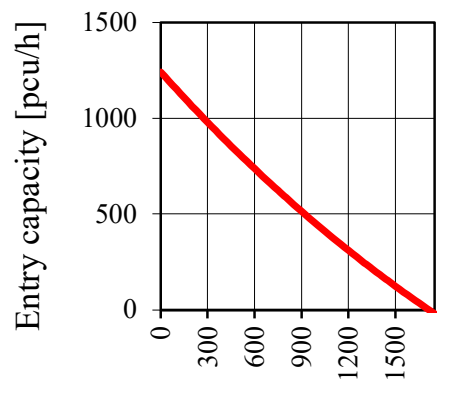

$\mathrm{Q}_{\mathrm{c}}[\mathrm{pcu} / \mathrm{h}]$

Vejdirektoratet

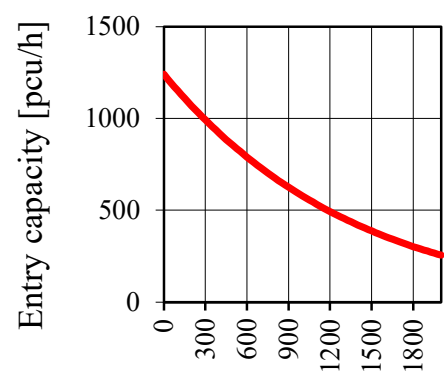

$\mathrm{Q}_{\mathrm{c}}[\mathrm{pcu} / \mathrm{h}]$

Figure 2: EC values according to the models of Tab. 1 with values in Tab. 2 


\section{Results and Discussion}

The main objective of the research is testing and comparing the models of Tab.1 for the test roundabout by means of total capacity (TC) evaluation. Actually, with respect to a given percentage origin/destination matrix $\mathbf{P}_{\mathrm{O} / \mathrm{D}}, \mathrm{TC}$ is the sum of the flows from each entry $Q_{e, i}$ that are simultaneously equal to $E C\left(Q_{e, i}=C_{i}\right)$, as in $E q(4)$ shown again below for the sake of simplicity:

$$
\mathrm{TC}=\sum_{\mathrm{i}=1}^{\mathrm{n}} \mathrm{Q}_{\mathrm{e}, \mathrm{i}} \quad \text { with } \quad \mathrm{Q}_{\mathrm{e}, \mathrm{i}} / \mathrm{C}_{\mathrm{i}}=1 \quad \mathrm{i}=1,2, \ldots, \mathrm{n}
$$

Entry flows to be considered in TC estimation are obtained by solving a system of equations in the $n$ unknowns $Q_{e, i}$. Each of these equations is obtained by writing the specific relation for the entry capacity of the model adopted (whose generic form is, as already indicated, $\mathrm{C}_{\mathrm{i}}=\mathrm{f}(\mathbf{Q}, \mathbf{G}, \boldsymbol{\Theta})$ and replacing $\mathrm{C}_{\mathrm{i}}$ with the unknown $\mathrm{Q}_{\mathrm{e}, \mathrm{i}}$. Due to the variety of mathematical expressions with which $\mathrm{C}_{\mathrm{i}}$ can be expressed, it is often appropriate to look for numerical solutions of the above system of equations, using for example iterative procedures (Mauro, 2010), as done in this research.

From what has been said, TC clearly depends on the shape of the $\mathbf{P}_{\mathrm{O} / \mathrm{D}}$ matrix. Figure 3 shows four distinct limit conditions of traffic flow distribution matrix, i.e.: $\mathrm{P}_{\mathrm{O} / \mathrm{D}} 1=100 \%$ of vehicles make the U-turn manoeuvre; $\mathrm{P}_{\mathrm{O} / \mathrm{D}} 2=100 \%$ of vehicles turn left; $\mathrm{P}_{\mathrm{O} / \mathrm{D}} 3: 100$ of vehicles cross the roundabout; $\mathrm{P}_{\mathrm{O} / \mathrm{D}} 4=100 \%$ of vehicles turn right.

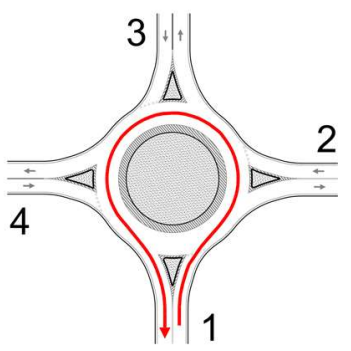

(A)

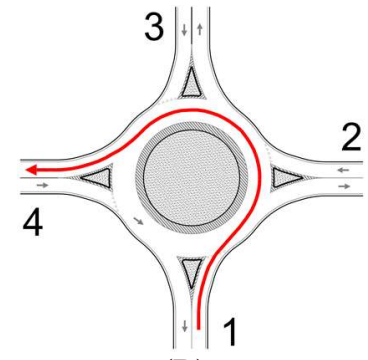

(B)

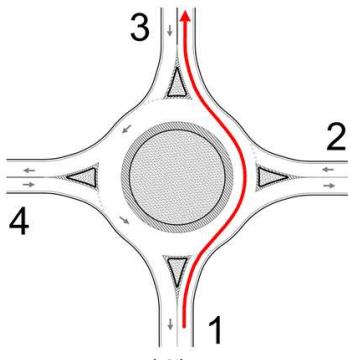

(C)

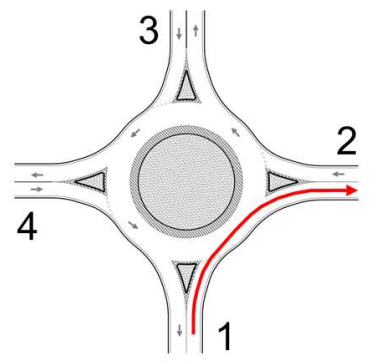

(D)

Figure 3: Exemplification of the limit conditions of traffic flow distribution entering from the arm $\mathrm{i}=1$ ((A): $\left.\mathrm{P}_{\mathrm{O} / \mathrm{D}} 1 ;(\mathrm{B}): \mathrm{P}_{\mathrm{O} / \mathrm{D}} 2 ;(\mathrm{C}): \mathrm{P}_{\mathrm{O} / \mathrm{D}} 3 ;(\mathrm{D}): \mathrm{P}_{\mathrm{O} / \mathrm{D}} 4\right)$

As can be observed from Fig. 4 and 5, the roundabout TC values increase from matrix $\mathrm{P}_{\mathrm{O} / \mathrm{D}} 1$ to matrix $\mathrm{P}_{\mathrm{O} / \mathrm{D}} 4$. Higher TC values occur when, for each arm, the entry flow turns right completely (i.e. matrix $\mathrm{P}_{\mathrm{O} / \mathrm{D}} 4$ ); in this condition, the maximum $\mathrm{TC}$ value is given by HCM 2016 model $(\mathrm{TC}=5,520 \mathrm{pcu} / \mathrm{h})$, which is also the most recent model. In the intermediate situation (i.e. matrix $\mathrm{P}_{\mathrm{O} / \mathrm{D}} 3$ ), the highest value is provided by the CERTU model $(\mathrm{TC}=3512 \mathrm{pcu} / \mathrm{h})$, which is one of the oldest among the models considered. Overall, considering the four traffic limit conditions, the model that is closest to the average TC calculated considering the 15 models is the Troutbeck model (Akçelik and Troutbeck, 1991), with an average absolute percentage deviation of less than $5 \%$. 


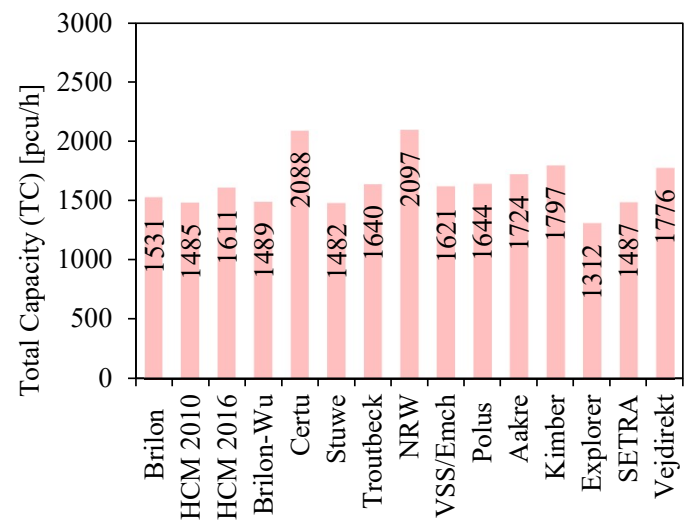

(A)

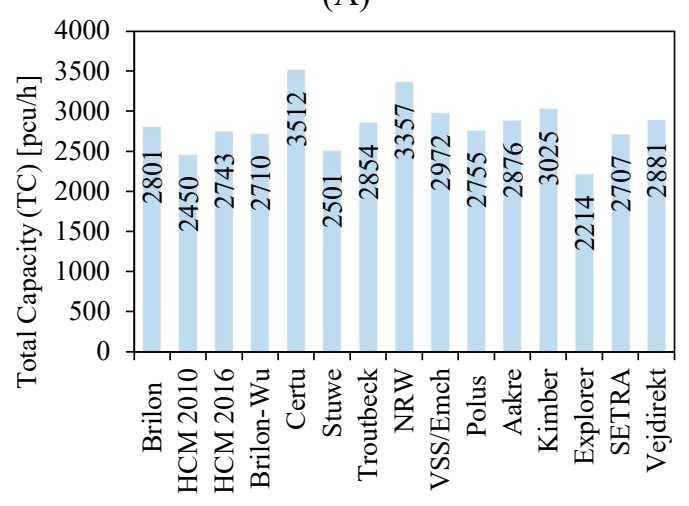

(C)

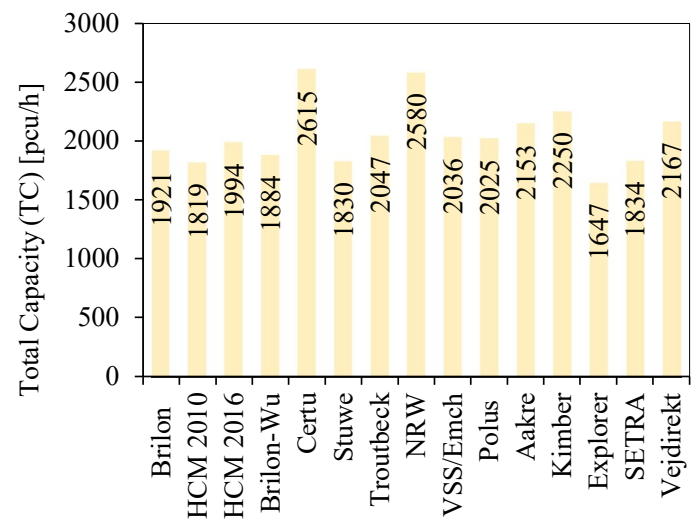

(B)

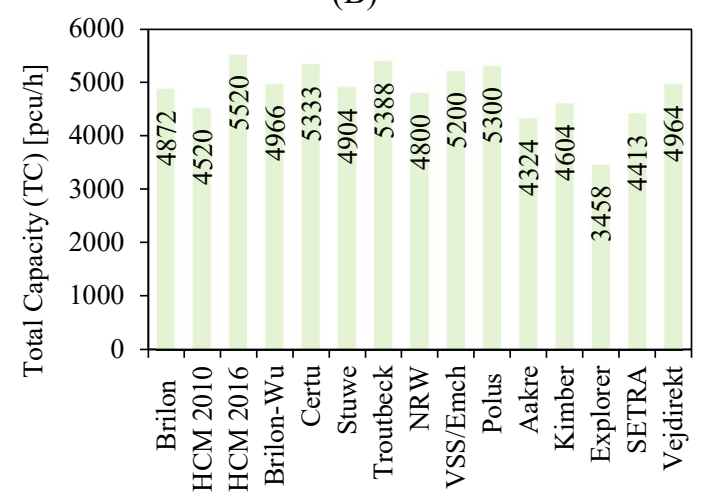

(D)

Figure 4: TC values (traffic flow distribution matrices (A): $\mathrm{P}_{\mathrm{O} / \mathrm{D}}$ 1; (B): $\mathrm{P}_{\mathrm{O} / \mathrm{D}} 2 ;(\mathrm{C}): \mathrm{P}_{\mathrm{O} / \mathrm{D}}$ 3; (D): $\left.\mathrm{P}_{\mathrm{O} / \mathrm{D}} 4\right)$

In this research, in addition to the four limit conditions in Fig. 3, a wide possibility of variation of the traffic distribution is explored by considering a great number of different $\mathbf{P}_{\mathrm{O} / \mathrm{D}}$ matrices. For this purpose, a Monte Carlo simulation has been performed considering 5,000 traffic distribution matrices, which have been used to process each EC model. Manoeuvring percentages have sampled from independent uniform probability distributions for each arm and then normalized. Thus, through Monte Carlo simulations we have obtained a large number of TC values for each model using again the iterative procedure in (Mauro, 2010). The results of these Monte Carlo iterations for each EC model highlight the probability distributions of TC from simulations.

More details about the sampled distribution of TC values can be observed for each model in Fig. 5 and 6. Explorer (Van Arem, 1992) and HCM 2010 (TRB, 2010) models give the lower TC values in all traffic conditions, while CERTU (1998) and NRW (Brilon et al., 1993) models offer the higher values. Instead, the values of TC distributions are very similar for the models SETRA (1987), HCM 2016 (TRB, 2016), Brilon (Brilon et al., 1993), Polus and Shmueli (1997). In each Montecarlo iteration, Troutbeck model (Akçelik and Troutbeck, 1991) shows a trend very close to the average distribution (Average Model), obtained by considering the sample average of the 15 capacity models. 


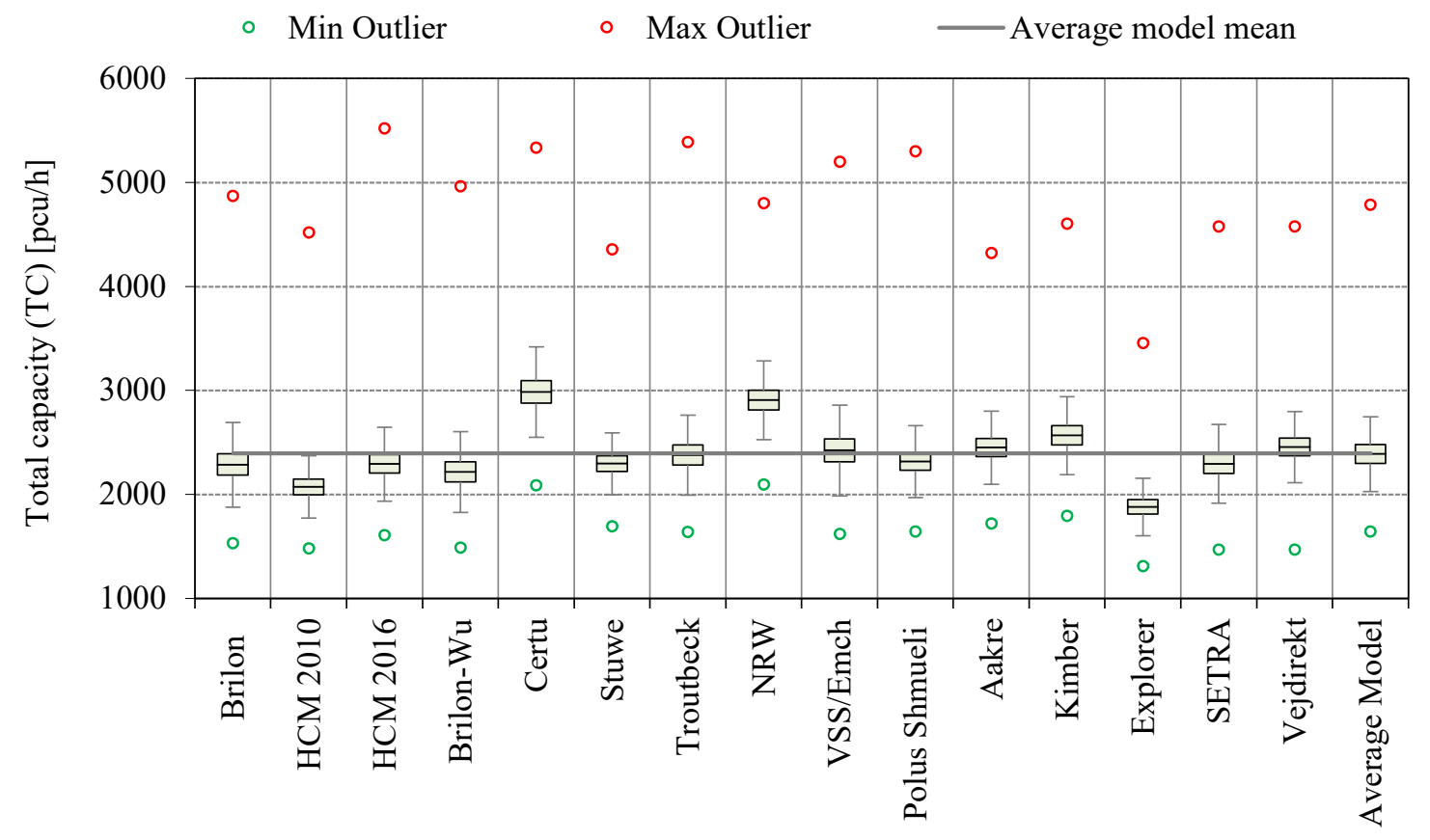

Figure 5: Distributions of the TC values (box plot)

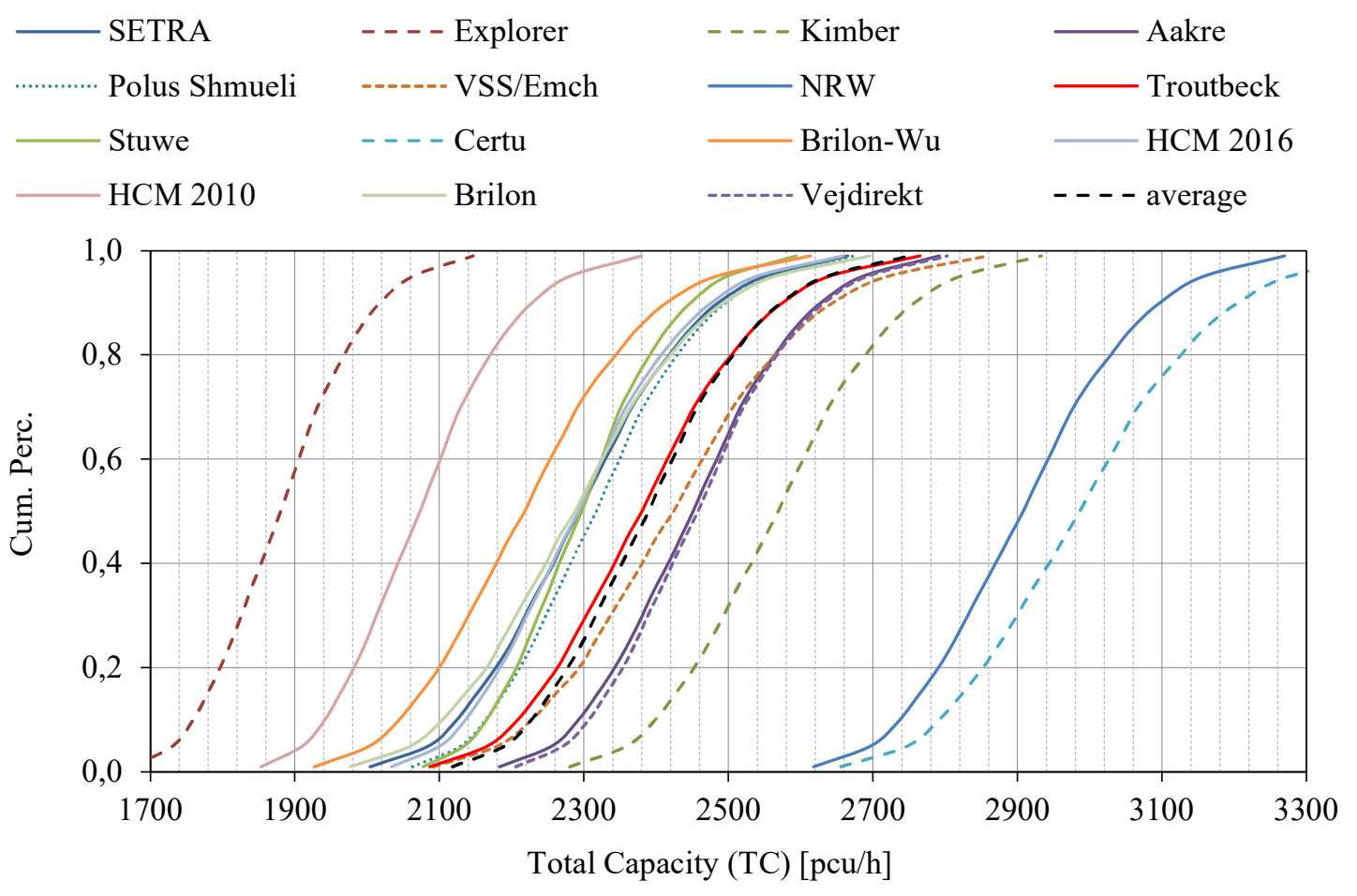

Figure 6: Sampled probability distribution for TC 


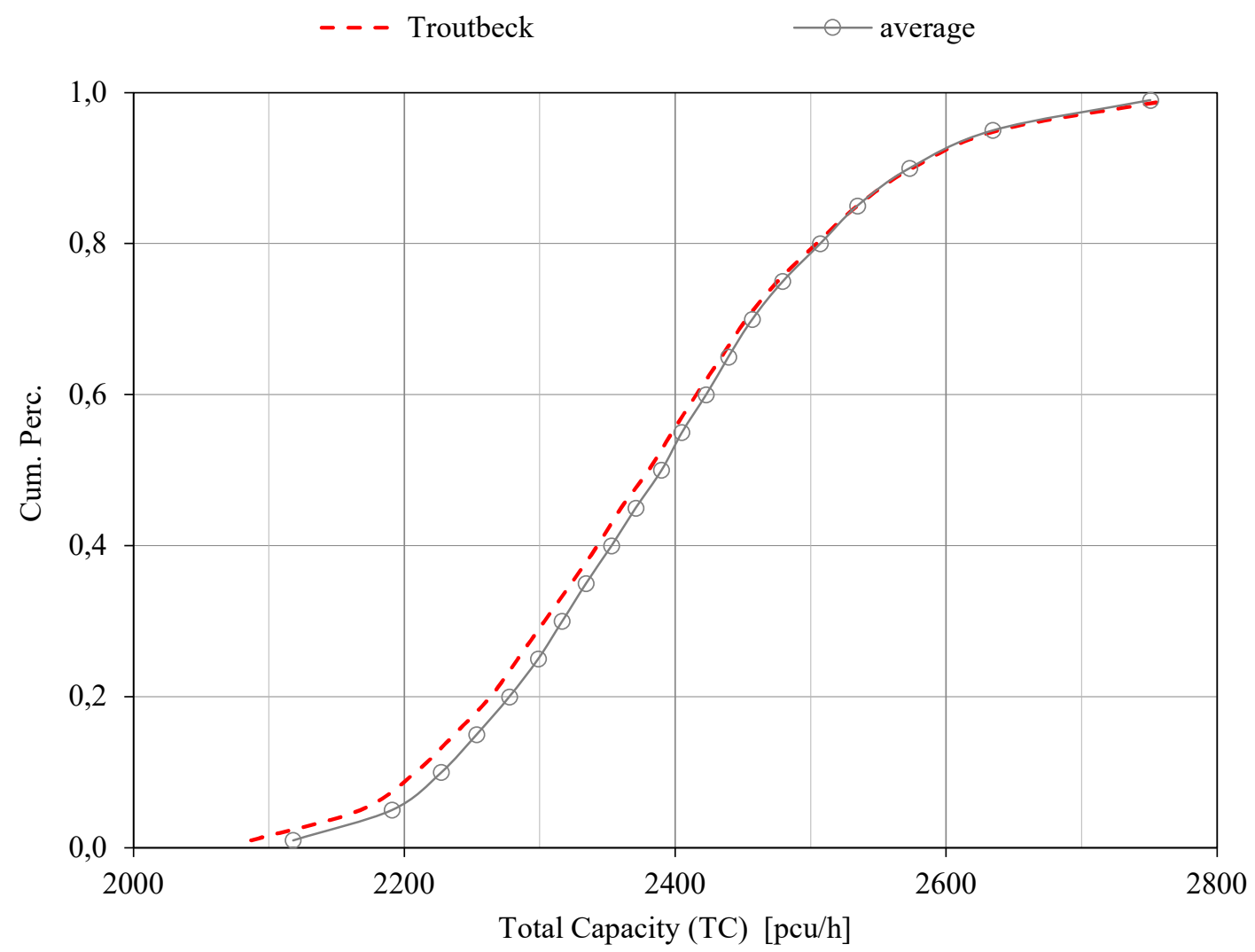

Figure 7: Troutbeck - Average models comparison for sampled TC distributions

The average model (AVE), which considers for each Monte Carlo iteration (and its related traffic distribution matrix) the mean value obtained considering the TC values of the fifteen models, can represent the most suitable estimate for roundabout TC. This is actually a value that can be assumed, in the absence of other information, when there is no other way to say whether a model among the most popular ones (i.e. the fifteen considered) can be preferred (as the most appropriate for the specific context) or if someone can be definitely excluded (as surely not appropriate to the specific context).

The similarity of the probability distributions of TC obtained with the Troutbeck model (Akçelik and Troutbeck, 1991) (T) and the average of the 15 models (AVE), is qualitatively well observable in Fig. 7. Due to the high number of samples, the two distributions show an evident Gaussian trend, respectively with means $\mu_{\mathrm{T}}=2,386$ and $\mu_{\mathrm{AVE}}=2,395$ and with standard deviations $\sigma_{\mathrm{T}}=151$ and $\sigma_{\mathrm{AVE}}=141$. These values are estimated considering the 5,000 sample values of the $\mathrm{T}$ model and the 5,000 average values of the 15 models defining the AVE model.

A more structured test to verify the similarity of the TC distributions has been carried out using a statistical measure of dissimilarity between probability distributions. In this case we consider the Bhattacharyya Distance (BD) (Bhattacharyya, 1943).

Considering that the sampled distributions, as mentioned, are substantially Gaussian (cf. Fig. 6), an overlapping test has been carried out between the TC probability distributions estimated for each of the fifteen models (M) and that of their average (AVE) using the Bhattacharyya Distance (BD) expression for Gaussian samples (Coleman and Andrews, 1979): 


$$
\mathrm{BD}(\mathrm{M}, \mathrm{AVE})=\frac{1}{4} \ln \left[\frac{1}{4}\left(\frac{\sigma_{\mathrm{M}}^{2}}{\sigma_{\mathrm{AVE}}^{2}}+\frac{\sigma_{\mathrm{AVE}}^{2}}{\sigma_{\mathrm{M}}^{2}}+2\right)\right]+\frac{1}{4}\left[\frac{\left(\mu_{\mathrm{AVE}}-\mu_{\mathrm{M}}\right)^{2}}{\sigma_{\mathrm{AVE}}^{2}+\sigma_{\mathrm{M}}^{2}}\right]
$$

where BD (M, AVE) is the Bhattacharyya distance between $\mathrm{M}$ and AVE TC sample distributions, $\mu_{\mathrm{AVE}}$ and $\mu_{\mathrm{M}}$ their sample mean and $\sigma_{\mathrm{AVE}}^{2}$ and $\sigma_{\mathrm{M}}^{2}$ their sample variance.

Figure 8 shows the BD values (in logarithmic scale) for each model compared to the average. The high similarity (in other words, a superimposition) between the probability distribution of TC according to the Troutbeck model (Akçelik and Troutbeck, 1991) and that according to the average of the 15 models is evident. In fact, the BD value obtained for Troutbeck model (Akçelik and Troutbeck, 1991) is extremely close to zero, as well as less than any other model.

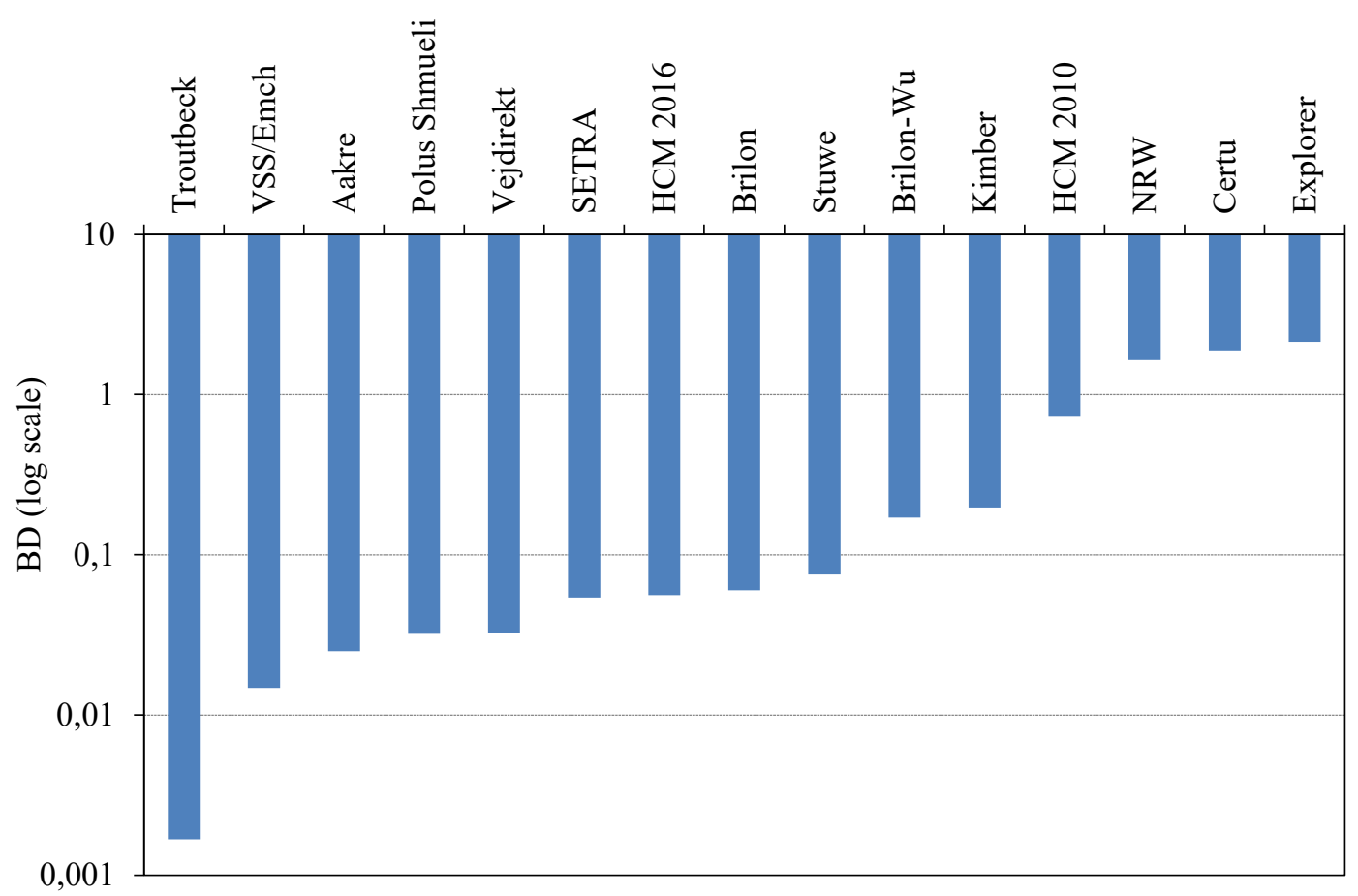

Figure 8: BD (logarithmic scale) for TC distributions compared to the average

In these terms, the Troutbeck model (Akçelik and Troutbeck, 1991) is the one that presents the probability distribution of total capacity that is closest to the average one, identifiable with respect to the fifteen models tested. Therefore, this model emerges as the best candidate to represent, in the conditions of the experiment (i.e., a diameter of 40 $\mathrm{m}$ and the working assumptions for the dimensional and modeling parameters as in Table 2 ), the average result obtainable with the fifteen most popular EC models applied to a single-lane and four-arm roundabout.

\section{Conclusion}

This study suggests a method for testing roundabout capacity models in terms of total capacity (TC). Fifteen entry capacity models have been tested for a conventional singlelane roundabout with four arms (external diameter $\mathrm{D}=40 \mathrm{~m}$ ). A great number of traffic 
simulations were performed, considering 5,000 traffic distribution test matrices $\left(\mathbf{P}_{\mathrm{O} / \mathrm{D}}\right)$ obtained by a Monte Carlo simulation, including the four limit conditions of traffic distribution.

A specific statistical analysis has been carried out. From the comparison between the TC distributions obtained with the fifteen models, the relative similarities and differences emerge. The results show that Explorer and the HCM 2010 models give the lower TC values, while CERTU and NRW models offer the higher values in all traffic conditions. The values of TC distributions are very similar for the models SETRA, HCM 2016, Brilon, Polus and Shmueli.

Troutbeck model shows a probability distribution for TC that is very close to the average distribution of the fifteen models, allowing to identify a suitable capacity formulation in view of practical applications, especially in absence of country-specific reference formulas. This evidence has also been confirmed by a statistical test of distribution dissimilarity (i.e., Bhattacharyya Distance).

Actually, these results are to be considered within the conditions assumed in this research. These concern a single lane roundabout; four entry/exit arms; a diameter of 40 $\mathrm{m}$ and the working assumptions for the dimensional and modeling parameters (see Table 2 ). In the continuation of the research, the analysis can be expanded by considering different layouts and exploring the effects of any variations in the dimensional and modeling parameters.

Therefore, at least in the case tested in this paper and not considering particular contextual situations that would lead to prefer a certain model (as it results certainly more suitable) or to exclude a certain group (as it collects models surely not conform to the specific case), Troutbeck model could be preferred and adopted especially in countries where the technical guidelines do not indicate specific capacity formulations for singlelane roundabout performance analysis.

\section{Nomenclature}

$\begin{array}{ll}\text { EC } & \text { entry capacity } \\ \mathbf{C}(\mathrm{t}) & \text { entry capacity vector } \\ \mathrm{C}_{\mathrm{i}}(\mathrm{t}) & \text { entry capacity for the generic arm } \\ \mathbf{Q} & \text { traffic demand vector } \\ \mathbf{G} & \text { geometric parameters vector } \\ \boldsymbol{\Theta} & \text { driver/vehicle parameters vector } \\ \mathrm{i} & \text { generic junction arm } \\ \mathrm{n} & \text { number of junction arms } \\ \mathrm{t} & \text { generic time instant } \\ \mathbf{Q}_{\mathrm{e}}(\mathrm{t}) & \text { entry traffic demand vector } \\ \mathrm{Q}_{\mathrm{ei}}(\mathrm{t}) & \text { entry traffic demand for the generic arm } \\ \mathbf{P}_{\mathrm{O} / \mathrm{D}}(\mathrm{t}) & \text { origin/destination percentage matrix } \\ \mathrm{P}_{\mathrm{ij}}(\mathrm{t}) & \text { percentage of traffic demand } \mathrm{Q}_{\mathrm{ei}}(\mathrm{t}) \text { directed to exit arm } \mathrm{j} \\ \mathbf{M}_{\mathrm{O} / \mathrm{D}}(\mathrm{t}) & \text { roundabout origin/destination traffic demand matrix } \\ \mathrm{Q}_{\mathrm{ij}}(\mathrm{t}) & \text { traffic demand from entry arm } \mathrm{i} \text { to exit arm } \mathrm{j} \\ \mathrm{TC} & \text { total capacity }\end{array}$




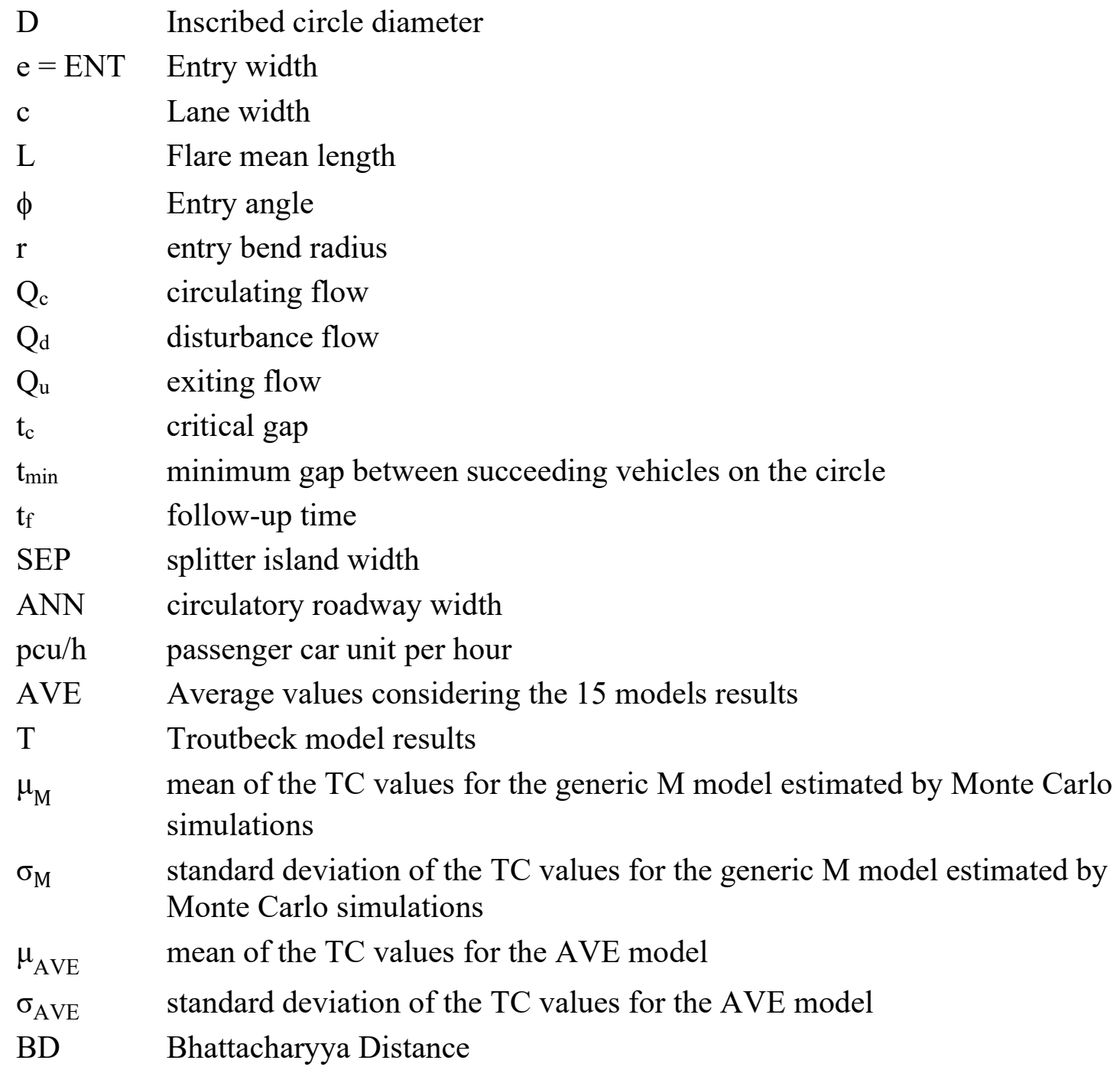

\section{References}

Aakre, A. (1997). "Norwegian methods for calculation of capacity and level of service at intersections". In: NORDKAP-Nordic Capacity Cooperation, University of Lund, Sverige, Sweden.

Akçelik, R., \& Troutbeck, R. (1991). "Implementation of the Australian roundabout analysis method in SIDRA". In: Highway Capacity and Level of Service-Proceedings of the International Symposium on Highway Capacity, Brannolte, U., Ed.; AA Balkema, Rotterdam, The Netherlands.

Bakhsh, A. (2020). "Traffic Simulation Modeling for Major Intersection". Sakarya University Journal of Science 24(1), 37-44, doi: 10.16984/saufenbilder.490984.

Banjanovic-Mehmedovic, L., Halilovic, E., Bosankic, I., Kantardzic, M., \& Kasapovic, S. (2016). "Autonomous vehicle-to-vehicle (v2v) decision making in roundabout using game theory". International Journal of Computer Science and Applications, 7, 292298, doi: 10.14569/IJACSA.2016.070840.

Behrisch, M., Bieker, L., Erdmann, J., \& Krajzewicz, D. (2020). SUMO-Simulation of Urban Mobility, Aerospace Center, Institute of Transportation Systems, Berlin, German. 
Bhattacharyya, A. (1943). "On a measure of divergence between two statistical populations defined by their probability distributions". Bulletin of the Calcutta Mathematical Society, 35, 99-109.

Bovy, H., Dietrich, K., \& Harman, A. (1991). “Guide Suisse des Giratoires”. Switzerland Guide to Roundabouts, Lausanne, Switzerland.

Brilon, W., Stuwe, B., \& Bondzio, R. (1993). Kleine Kreisverkehre-Empfehlungen zum Einsatz und zur Gestaltung; Ministerium Stadtentwicklung und Verkehr des Landes $N R W$, Duisburg, Germany.

Brilon, W., Stuwe, B., \& Drews, O. (1993). Sicherheit und Leistungsfähigkeit von Kreisverkehrsplätzen; Institute for Traffic Engineering, Ruhr Universität, Bochum, Deutschland.

Capasso, A.P., Bacchiani, G., \& Molinari, D. (2020). "Intelligent roundabout insertion using deep reinforcement learning". ICAART 2020. In Proceedings of the 12th International Conference on Agents and Artificial Intelligence, Valletta, Malta, 22-24 February 2020, Volume 2, pp. 378-385, doi: 10.5220/0008915003780385

Centre d'études sur les réseaux, les transports, l'urbanisme et les constructions publiques (CERTU). (1998). "Conception des Carrefours à Sens Giratoire Implantés en Milieu Urbain". Ministère de l'Equipement, du Logement, de l'Aménagement du Territoire et des Transports; Centre d'Études des Transports Urbains (CETUR): Lyon, France.

Coleman, G. B., \& Andrews, H. C. (1979). "Image segmentation by clustering". Proceedings of the IEEE, 67(5), 773-785, doi: 10.1109/PROC.1979.11327.

Doniec, A., Mandiau, R., Piechowiak, S., \& Espié, S. (2008). "A behavioral multi-agent model for road traffic simulation". Engineering Applications of Artificial Intelligence, 21, 1443-1454, doi: 10.1016/j.engappai.2008.04.002.

Gallelli V., Iuele T., Vaiana R., Vitale A. (2017). "Investigating the Transferability of Calibrated Microsimulation Parameters for Operational Performance Analysis in Roundabouts". Journal of Advanced Transportation, vol. 2017, p. 1-10, ISSN: 20423195, doi: 10.1155/2017/3078063.

Gritschneder, F., Hatzelmann, P., Thom, M., Kunz, F., \& Dietmayer, K. (2016). "Adaptive learning based on guided exploration for decision making at roundabouts". In Proceedings of the 2016 IEEE Intelligent Vehicles Symposium, Gotenburg, Sweden, 19-22 June 2016, Volume 7535422, pp. 433-440, doi: 10.1109/IVS.2016.7535422.

Guo, R., Liu, L., \& Wang, W. (2019). "Review of roundabout capacity based on gap acceptance". Journal of Advanced Transportation, Volume 2019, Article ID 4971479, doi:10.1155/2019/4971479.

TRB (2010). Highway Capacity Manual, 5th ed. Washington, DC, USA.

TRB (2016). Highway Capacity Manual, 6th ed. Washington, DC, USA.

Kimber, R.M. (1980). “The Traffic Capacity of Roundabouts”. TRRL Report LR942. Transport and Road Research Laboratory, Crowthorne, UK.

Macioszek, E. (2020). "Roundabout entry capacity calculation-a case study based on roundabouts in Tokyo, Japan, and Tokyo surroundings". Sustainability, 12, 1533, doi: $10.3390 / \mathrm{su} 12041533$.

Małecki K. (2017). The Use of Heterogeneous Cellular Automata to Study the Capacity of the Roundabout. In: Rutkowski L., Korytkowski M., Scherer R., Tadeusiewicz R., Zadeh L., Zurada J. (eds) Artificial Intelligence and Soft Computing. ICAISC 2017. Lecture Notes in Computer Science, vol 10246, Springer, Cham. https://doi.org/10.1007/978-3-319-59060-8_28 
Mauro, R. (2010). Calculation of Roundabouts: Capacity, Waiting Phenomena and Reliability; Springer Science \& Business Media, Berlin/Heidelberg, Germany, doi: 10.1007/978-3-642-04551-6.

Mauro, R., \& Pompigna, A. (2020). "State of the art and computational aspects of timedependent waiting models for non-signalised intersections". Journal of Traffic and Transportation Engineering (English Edition), doi: 10.1016/j.jtte.2019.09.007.

Polus, A., \& Shmueli, S. (1997). "Analysis and Evaluation of the Capacity of Roundabouts". Transportation Research Record, 1572, 99-104.

Pompigna, A., \& Rupi, F. (2015). "Differences between HCM procedures and fundamental diagram calibration for operational los assessment on Italian freeways". Transportation Research Procedia, 5, pp. 103-118, doi: 10.1016/j.trpro.2015.01.016.

Pompigna, A., \& Rupi, F. (2017). "Lane-distribution models and related effects on the capacity for a three-lane freeway section: Case study in Italy". Journal of Transportation Engineering, 143 (10), 05017010, doi: 10.1061/JTEPBS.0000080.

Pompigna, A., Guerrieri, M., \& Mauro, R. (2020). "New Extensions and Applications of the Modified Chumanov Model for Calculating Entry Capacity of Single-Lane Roundabouts". Sustainability, 12, 6122, doi: 10.3390/su12156122.

PTV Group. (2019). Vissim (Verkehr In Städten-SIMulationsmodell); PTV: Karlsruhe, Germany.

Service d'Etudes Techniques des Routes et Autoroutes (SETRA). (1987). Capacité des Carrefour Giratoires Interurbains: Prémiers Résultats; Note d'information n. 44; SETRA: Bagneux, France.

SIAS. (2019). Paramics Microsimulation. S-Paramics (Parallel Microscopic Traffic Simulator). Edinburgh, UK.

Stuwe, B. (1991). "Capacity and safety of roundabouts-German results". In: Brilow, W., (Ed.) Intersections without Traffic Signals II. Springer: Berlin/Heidelberg, Germany.

Tian, R., Li, S., Li, N., Kolmanovsky, I., Girard, A., \& Yildiz, Y. (2018). “Adaptive gametheoretic decision making for autonomous vehicle control at roundabouts". In: Proceedings of the 2018 IEEE Conference on Decision and Control (CDC), Miami Beach, FL, USA, 17-19 December 2018, IEEE, Piscataway, NJ, USA, pp. 321-326, doi: 10.1109/CDC.2018.8619275.

Tollazzi, T., Mauro, R., Guerrieri, M., \& Renčelj, M. (2016). "Comparative analysis of four new alternative types of roundabouts: "Turbo", "flower", "target" and "fourflyover" roundabout". Periodica Polytechnica Civil Engineering, 60, 51-60, doi: 10.3311/PPci.7468.

TSS-Transport Simulation Systems. (2019). Aimsun (Advanced Interactive Microscopic Simulator for Urban and Non-Urban Networks); Transport Simulation Systems, Barcelona, Spain.

Van Arem, B. (1992). Background of the Program Roundabout Explorer; Instituut voor Ruimtelijke Organisatie TNO, Delft, The Netherlands.

Vejdirektoratet. (1999). Kapacitet og serviceniveau: Baggrund og documentation. Capacity and Level of Service: Background and Documentation; Trafikteknik, Vejregelrådet, København, Danmark.

Wang, R., Zhang, W., \& Miao, Q. (2005). "Effects of driver behavior on traffic flow at three-lane roundabouts". The International Journal of Intelligent Control and Systems, 10 (2), 123-130.

Yap, Y.H., Gibson, H.M., \& Waterson, B.J. (2013). "An international review of roundabout capacity modelling”. Transportation Reviews, 33 (5), 593-616, doi: 10.1080/01441647.2013.830160. 
European Transport $\backslash$ Trasporti Europei (2020) Issue 80, Paper n ${ }^{\circ}$ 7, ISSN 1825-3997

Zhao, M., Kathner, D., Jipp, M., Soffker, D., \& Lemmer, K. (2017). "Modeling driver behavior at roundabouts: Results from a field study". In: Proceedings of the 2017 IEEE Intelligent Vehicles Symposium, Redondo Beach, CA, USA, 11-14 June 2017; Volume 7995831, pp. 908-913, doi: 10.1109/IVS.2017.7995831.

Acknowledgements

The authors would like to thank Gérard Louah, former at the Service d'Etudes Techniques des Routes et Autoroutes (SETRA), France and at Les Centres d'Etudes Techniques de l'Equipement (CETE) de l'Ouest, France for the constructive feedbacks. 